\title{
Ouvidorias públicas no Brasil: o elo entre o direito de acesso à informação e a efetivação da proteção de dados pessoais no setor público
}

rdai.com.br/index.phph/rdai/article/view/428

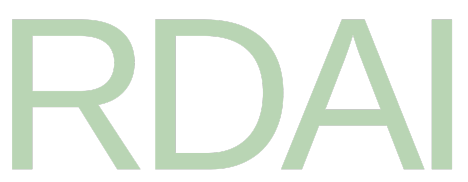

\section{Autores}

- José Sérgio da Silva Cristóvam Universidade Federal de Santa Catarina (Florianópolis, Santa Catarina, Brasil)

- Tatiana Meinhart Hahn Universidade Federal de Santa Catarina (Florianópolis, Santa Catarina, Brasil)

\section{DOI:}

https://doi.org/10.41143/rdai.19.j.jssc

\section{Palavras-chave:}

Ouvidorias públicas, Acesso à informação, Proteção de dados pessoais, LGPD, Administração pública, ANPD

\section{Resumo}

O estudo pretende analisar o papel das ouvidorias na efetivação da proteção de dados pessoais no setor público, a partir das suas atribuições legais e dos procedimentos previstos na legislação aplicável, em especial a Lei 12.527, de 2011, a Lei 13.460, de 2017, e a Lei 13.709, de 2018, e seus respectivos regulamentos. Para tanto, são discutidas três questões que despontam como centrais: (i) quais as características e as atribuições legais das ouvidorias públicas no Brasil?; (ii) quais as atribuições das ouvidorias com a vigência da Lei 13.709 e da ouvidoria instalada junto à ANPD, e como ambas devem contribuir com a efetivação do direito de proteção de dados pessoais no setor público? e (iii) como equacionar as funções do ouvidor, do encarregado e do controlador na implantação das normas da LGPD no setor público? A análise desses temas possibilita uma interessante aproximação da realidade prática da proteção de dados pessoais no setor público, a partir da concepção de que a ouvidoria pública é um elo central de comunicação do cidadão com o Estado, enquanto instrumento de controle sobre violações a esse direito e das funções regulatórias da ANPD. A metodologia adotada é a dedutiva e a técnica de pesquisa é indireta com fonte bibliográfica. 


\section{Biografia do Autor}

\section{José Sérgio da Silva Cristóvam, Universidade Federal de Santa Catarina (Florianópolis, Santa Catarina, Brasil)}

Professor na Universidade Federal de Santa Catarina (Florianópolis, Santa Catarina, Brasil) de Direito Administrativo (Graduação, Mestrado e Doutorado). Mestre e Doutor em Direito pela UFSC, com Doutoramento-Sanduíche junto à Universidade de Lisboa (Portugal). Subcoordenador do PPGD/UFSC. Conselheiro Federal da OAB/SC. Presidente da Comissão de Direito Administrativo da OAB Nacional. Coordenador do Grupo de Estudos em Direito Público (GEDIP/UFSC). Advogado em Santa Catarina.

o000-0001-8232-9122 | jscristovam@gmail.com

\section{Tatiana Meinhart Hahn, Universidade Federal de Santa Catarina (Florianópolis, Santa Catarina, Brasil)}

Mestranda da Universidade Federal de Santa Catarina (Florianópolis, Santa Catarina, Brasil) em Direito Administrativo pelo PPGD/UFSC. Especialista em Direito Público (IMED) e Master Business Administration em Comércio e Relações Internacionais (UCS). Estudou na Universitá degli Studi di Roma, Itália e na Universidad Argentina de La Empresa. Integra o Grupo de Estudos em Direito Público (GEDIP/UFSC). Procuradora Federal.

oooo-0001-6097-24.91 | hahn.tatiana@gmail.com

\section{Referências}

ALVES, Fabrício da Mota. Estruturação do cargo de DPO em entes públicos. In: VAINZOF, Rony; BLUM, Renato Opice; MORAES, Henrique Fabretti (Coord.). Data protection officer (encarregado): teoria e prática de acordo com a LGPD e o GDPR. São Paulo: Ed. RT, 2020.

ANDRADE, Mariana Dionísio de; NETO, Lásaro Arsênio de Paula Aragão. Por que é tão complicada a aplicação efetiva do processo de accountability no Brasil? Revista Quaestio Iuris, Rio de Janeiro, v. 12, n. 1, p. 122-143, 2019.

BECK, Ulrich. Sociedade de risco: rumo a uma outra modernidade. Trad. Sebastião Nascimento. 2. ed. São Paulo: Editora 34, 2011.

BEZERRA, Helga Maria Saboia. Defensor do povo: origens do instituto do ombudsman e a malograda experiência brasileira. Revista Direito, Estado e Sociedade, Rio de Janeiro, n. 36, p. 46- 73, 2010.

BIONI, Bruno Ricardo. Proteção de dados pessoais: a função e os limites do consentimento. 2. ed. rev., atual. Rio de Janeiro: Forense, 2019.

CRISTÓVAM, José Sérgio da Silva; HAHN, Tatiana Meinhart. Administração Pública orientada por dados: governo aberto e infraestrutura nacional de dados abertos. Revista de Direito Administrativo e Gestão Pública, [S.1.], v. 6, n. 1, p. 1-24, jan.-jun. 2020. 
Disponível em: [www.indexlaw.org/index.php/rdagp/article/view/6388/pdf]. Acesso em: 17.07.2021.

CRISTÓVAM, José Sérgio da Silva; HAHN, Tatiana Meinhart. O processo infeccioso da Covid-19 no regime de dados no Brasil: a LGPD como vacina em teste no tratamento de dados pessoais no setor público. Revista Brasileira de Direito, Passo Fundo, v. 16, n. 3, p. 1-19, set.-dez. 2020. Disponível em:

[[https://seer.imed.edu.br/index.php/revistadedireito/article/view/4306/2682]. Acesso em: 17.07.2021.

CRISTÓVAM, José Sérgio da Silva; SAIKALI, Lucas Bossoni; SOUSA, Thanderson Pereira de. Governo Digital na implementação de serviços públicos para a concretização de direitos sociais no Brasil. Revista Seqüência, Florianópolis, n. 84, p. 209-242, abr. 2020.

CRISTÓVAM, José Sérgio da Silva; HAHN, Tatiana Meinhart. A transparência no tratamento de dados pessoais pela administração pública: o lapidário e o diamante bruto. In: CRISTÓVAM, José Sérgio da Silva; et al. (Coord.). Direito administrativo contemporâneo: diálogos Brasil e México. Florianópolis: Habitus, 2020.

CRISTÓVAM, José Sérgio da Silva; CASIMIRO, Lígia Maria Silva Melo de; SOUSA, Thanderson Pereira de. Política de governança pública federal: adequação, modelo de gestão e desafios. In: CRISTÓVAM, José Sérgio da Silva; NIEBUHR, Pedro de Menezes; SOUSA, Thanderson Pereira de (Org.). Direito administrativo em transformação. Florianópolis: Habitus, 2020.

CYRILLO, Rose Meire. Ouvidorias: um aporte necessário. Revista do Ministério Público do Distrito Federal e Territórios, Brasília, n. 9, p. 192-211, 2015.

GOMES, Manoel Eduardo Alves Camargo e. A institucionalização no ombudsman no Brasil. Revista de Direito Administrativo, Rio de Janeiro, v. 167, p. 1-21, 1987.

GOMES, Manoel Eduardo Alves Carmago e. O regime jurídico das ouvidorias públicas brasileiras: causalidade de sentido e adequação estruturo-funcional. Tese (Doutorado em Direito) - Universidade Federal de Santa Catarina, Florianópolis, 2000.

HABERMAS, Jürgen. Passado como futuro. Trad. Flávio Beno Siebeneichler.. Rio de Janeiro: Tempo Brasileiro, 1993 (Coleção Biblioteca Tempo Universitário, n. 94. Série Estudos Alemães).

IGNÁCIO, Sergio Aparecido. Importância da estatística para o processo de conhecimento e tomada de decisão. Revista Paranaense de Desenvolvimento, Curitiba, n. 118, p. 175-192, 2010.

MARTINS, Ricardo Marcondes. Lei Geral de Proteção de Dados Pessoais e direito administrativo: questões polêmicas. In: POZZO, Augusto Neves Dall; MARTINS, Ricardo Marcondes (Coord.). LGPD e Administração Pública: uma análise ampla dos impactos. São Paulo: Ed. RT, 2020. 
MARTINS JUNIOR, José Isidoro. História do direito nacional. Rio de Janeiro: Typographia da Empreza Democratica Editora, 1895.

MENEZES, Ronald do Amaral. A atuação das ouvidorias públicas federais como instâncias de controle e participação social no Brasil. Texto para Discussão n. 2286. Brasília: Instituto de Pesquisa Econômica Aplicada, 2017.

MOLINARO, Carlos Alberto; SARLET, Ingo Wolfgang. Direito à informação e direito de acesso à informação como direitos fundamentais na constituição brasileira. Revista da AGU, Brasília, v. 13, n. 42, p. 9-38, 2014.

NISSENBAUM, Helen. Technology, policy, and the integrity of social life. Stanford: Stanford University Press, 2010. Disponível em:

[https://crypto.stanford.edu/portia/papers/privacy in context.pdf]. Acesso em: 10.11.2020.

O’DONNELL, Guillermo. Accountability horizontal e novas poliarquias. Lua Nova: Revista de Cultura e Política, São Paulo, n. 44, p. 27-54, 1998.

PÉREZ LUÑO, Antonio Enrique. Ciberciudanía o ciudadanía.com? Barcelona: Gedisa, 2004 .

REIF, Linda C. The ombudsman, good governance, and the international human rights system. The Netherlands: Martinus Nijhoff Publishers, 2004.

SARLET, Ingo Wolfgang. O direito fundamental à proteção de dados. In: DONEDA, Danilo et al. (Coord.). Tratado de proteção de dados pessoais. Rio de Janeiro: Forense, 2020.

SARLET, Ingo Wolfgang. Constituição e proporcionalidade: o direito penal e os direitos fundamentais entre proibição de excesso e de insuficiência. Revista de Estudos Criminais , Sapucaia do Sul, n. 12, ano 3, p. 86-120, 2003.

TÁCITO, Caio. O controle da administração e a nova constituição do Brasil. Revista de Direito Administrativo, Rio de Janeiro, v. 90, p. 23-29, 1967.

TÁCITO, Caio. Transformações do direito administrativo. Revista de Direito Administrativo, Rio de Janeiro, v. 242, p. 151-158, 2005.

UGGLA, Fredrik. The ombudsman in Latin America. Journal of Latin American Studies, [S.l.], v. 36, n. 3, p. 423-450, 2004.

VOLIO, Lorena González. The institution of the ombudsman: The Latin American experience. Revista IDDH, Costa Rica, n. 37, p. 219-248, 2003.

\section{Publicado}




\section{Como Citar}

CRISTÓVAM, J. S. da S.; HAHN, T. M. Ouvidorias públicas no Brasil: o elo entre o direito de acesso à informação e a efetivação da proteção de dados pessoais no setor público:

Public ombudsmen in Brazil: the link between the right of access to information and the effectiveness of the protection of personal data in the public sector. Revista de Direito Administrativo e Infraestrutura | RDAI, São Paulo: Thomson Reuters - Livraria RT, v. 5, n. 19, p. 159-189, 2021. DOI: 10.48143/rdai.19.jssc. Disponível em:

https://rdai.com.br/index.php/rdai/article/view/428. Acesso em: 7 fev. 2022.

\section{Edição}

\section{V.5_n. 19_(2021).}

\section{Seção}

Direito Administrativo: Controle

\section{Licença}

\section{(1) $\Theta \Theta$}

Este trabalho está licenciado sob uma licença Creative Commons Attribution-

NonCommercial-NoDerivatives 4.0 International License.

(CC BY-NC-ND)

Este é um resumo (e não um substituto) da licença

Regras para publicaçãão

Direitrizes Editoriais

Direitos e Deveres

Errata e Retratação

Preservação e Plagiarismo

Revisão e Avaliaçãa 
